Article

\title{
Molecular Characterization, Tissue Distribution and Differential Nutritional Regulation of Three n-3 LC-PUFA Biosynthesis-Related Genes in Hybrid Grouper (Epinephelus fuscoguttatus $+\times$ Epinephelus lanceolatus $\left.\sigma^{\top}\right)$
}

\author{
Qingjun Wu, Zhi Zheng, Chuijin Wang, Yao Wang, Yuejia Sun and Yujie Gao *
}

check for updates

Citation: Wu, Q.; Zheng, Z.; Wang, C.; Wang, Y.; Sun, Y.; Gao, Y. Molecular Characterization, Tissue Distribution and Differential Nutritional Regulation of Three n-3 LC-PUFA Biosynthesis-Related Genes in Hybrid Grouper (Epinephelus fuscoguttatus $q \times$ Epinephelus lanceolatus $\sigma^{7}$ ). Animals 2022, 12, 234. https://doi.org/ 10.3390/ani12030234

Academic Editors: Esmail Lutfi, Emilio J. Vélez and Kenji Saitoh

Received: 2 December 2021 Accepted: 5 January 2022

Published: 19 January 2022

Publisher's Note: MDPI stays neutral with regard to jurisdictional claims in published maps and institutional affiliations.

Copyright: (C) 2022 by the authors. Licensee MDPI, Basel, Switzerland. This article is an open access article distributed under the terms and conditions of the Creative Commons Attribution (CC BY) license (https:// creativecommons.org/licenses/by/ $4.0 /)$.
College of Marine Science, Hainan University, Haikou 570228, China; 19090800210014@hainanu.edu.cn (Q.W.); 18090800210019@hainanu.edu.cn (Z.Z.); wangchuijin888@163.com (C.W.); 18152235096@163.com (Y.W.); 19095134210029@hainanu.edu.cn (Y.S.)

* Correspondence: yujiegao@hainanu.edu.cn

Simple Summary: Polyunsaturated fatty acids, especially DHA and EPA, play crucial roles in fish growth performance, brain and eye development, reproduction and non-specific immune responses. However, considering the environmental unsustainability and the increasing price of fisheries' byproducts, alternative aquafeed ingredients are needed as a source of unsaturated fatty acids for farming marine fish. Here, we isolated and characterized three genes participating in the biosynthesis of n-3 LC-PUFA in hybrid groupers. We found that these genes were expressed in the liver of hybrid groupers in response to dietary fatty acid levels. Our findings contribute to a better understanding of the n-3 LC-PUFA biosynthesis process in this marine fish species.

\begin{abstract}
Elongases of very long-chain fatty acids (Elovls) and fatty acid desaturases (Fads) are crucial enzymes involved in the biosynthesis of long-chain polyunsaturated fatty acids (LC-PUFAs). In this paper, we report the molecular cloning and characterization of three genes from the marine teleost Epinephelus fuscoguttatus $+\times$ Epinephelus lanceolatus $\sigma^{7}$, and analyzed tissue distribution and their expression in response to dietary n-3 LC-PUFA levels after a 42-day feeding experiment. The elovl5, elovl 8 and fads2 genes encoded 294, 263 and 445 amino acids, respectively, which exhibited all the characteristics of the Elovl and Fads family. Tissue distribution analysis revealed that elovl5, elovl 8 and fads 2 were widely transcribed in various tissues, with the highest level in the brain, as described in other carnivorous marine teleosts. The transcript levels of elovl5, elovl8 and fads2 in the liver were significantly affected by dietary n-3 LC-PUFA, and higher LC-PUFA levels repressed their expression. These results demonstrated, for the first time, the presence and nutritional modulation of elovl5, elovls and fads 2 cDNA in the juvenile hybrid grouper. Further studies are needed to determine the functional characterization of these genes and explore the mechanism of these genes when regulated by dietary fatty lipid profiles in this species.
\end{abstract}

Keywords: Serranidae; cross-breeding; synthesis pathway; RACE cloning; differentially expressed gene

\section{Introduction}

Long-chain polyunsaturated fatty acids (LC-PUFA, $\geq$ C20 and $\geq 2$ double bonds) are widely present in organisms and play vital roles in maintaining cell membrane fluidity, regulating fat metabolism, enhancing immunity and reducing inflammation [1]. Among these, eicosapentaenoic acid (EPA) and docosahexaenoic acid (DHA) are the most critical LC-PUFAs, with beneficial effects on human health particularly in the prevention of cardiovascular and neuro developmental disorders [2]. At present, fish, particularly marine species, represent a rich source of EPA and DHA for human consumers, due to the high content of LC-PUFAs acquired from the feed [3]. However, the raw materials for 
aquaculture feed have reached a sustainable limit, and there is a rapid and continuous growth in aquaculture activities; it is estimated that $75 \%$ of the world's fish oil supplies are used for aquaculture production [4]. Thus, aquaculture nutritionists and aqua-feed companies are seeking sustainable alternatives to replace marine fish oil. However, the other issue is that the alternatives, primarily plant oils rich in C18 PUFA but devoid of LC-PUFA significantly decreased n-3 LC-PUFA in the filet of farmed fish [5,6]. Therefore, there is considerable interest in understanding the n-3 LC-PUFA biosynthesis pathway and nutritional regulation mechanism in the cultured fish species.

LC-PUFA biosynthesis depends on the specific gene repertoire and each enzyme's respective functional capabilities, which may vary from species to species [7]. Elovls are the initial and rate-limiting enzymes responsible for the elongation reaction required for the $d e$ novo biosynthesis of LC-PUFA. At present, the Elovls family was found to have Elov11-8, in which Elov12, Elov14, Elov15 and Elov18 are involved in the elongation of LC-PUFA [8-10]. Elov12 is preferentially responsible for the elongation step from C22 to C24 LC-PUFA. It has been found in freshwater and anadromous species such as zebrafish (Danio rerio), African catfish (Clarias gariepinus), and Atlantic salmon (Salmo salar), as well in chordates such as sea lamprey (Petromyzon marinus, agnathan) and the elephant shark (Callorhinchus milii, basal gnathostome) [11-14]. Thus, the variation between marine and freshwater fish species in the presence or absence of Elov12, a critical enzyme for DHA synthesis, was hypothesized to contribute to the low ability of most farmed marine fish to biosynthesize DHA [15].

Elov14 and Elov15 have been isolated from several marine fish species [16]. Elovl5 can preferentially elongate C18 (18:3n-6 and 18:4n-3) and C20 (20:4n-6 and EPA) fatty acids but has low activity toward C22 fatty acids [17]. Elovl4 can effectively extend C18 PUFAs and participate in the synthesis of DHA. Accordingly, it is expected that this enzyme could compensate for Elovl2 activity in some marine fish species, such as rabbitfish (Siganus canaliculatus) [18]. Recently, two Elovl8 isoforms, "Elovl8a" and "Elovl8b", have been found in zebrafish [9] and rabbitfish [19]. Further functional characterization by heterologous expression in yeast showed that Elovl8b could elongate $C 18$ (18:2n-6, 18:3n-3 and 18:4n-3) and C20 (20:4n-6 and 20:5n-3) polyunsaturated fatty acids (PUFAs) to longer-chain polyunsaturated fatty acids (LC-PUFAs), whereas Elovl8a lacked this ability in rabbitfish. However, studies in CRISPR/Cas9 Elovl8a $\mathrm{a}^{-/-}$and Elovl8b $\mathrm{b}^{-/-}$zebrafish revealed that Elov18a activity was specific to C18-C20 PUFAs and Elovl8b activity was specific to C18:0 and C20:1 MUFAs. Fatty acid desaturase enzymes introduce double bonds into specific positions on the carbon chain to produce desaturation and are crucial to the synthesis of DHA and 22:5n-6 from EPA and 22:4n-6, respectively, via the "Sprecher pathway" [20]. The Fads gene family was found to have Fads1-3 [21]. However, in most of the teleost species, only Fads 2 was present, and this enzyme was more similar to mammalian $\Delta 6$ desaturase in most fish species [22]. Therefore, to compensate for the loss of Fads1, some teleost Fads2 have exhibited additional desaturase activity, such as $\Delta 5$ in rainbow trout [23], $\Delta 6 / \Delta 5$ and $\Delta 4$ in rabbitfish [24], and $\Delta 4$ in Senegalese sole (Solea senegalensis, 1858) [25].

Grouper aquaculture is an important sector of marine fish production in China, with about 190,000 $\mathrm{t}$ being produced yearly [26]. Among these, a hybrid grouper of tiger grouper (Epinephelus fuscoguttatus \%) and giant grouper (Epinephelus lanceolatus $\sigma^{r}$ ) have become the dominant cultivated species due to their rapid growth and high disease resistance characters [27]. However, to our knowledge, little information is available regarding the genes involved in LC-PUFA biosynthesis in this fish species. Previous studies in a similar species, the orange-spotted grouper (Epinephelus coioides), have suggested that it has a limited ability to synthesize n-3 LC-PUFA, especially DHA [28,29]. Thus, to fully understand the LC-PUFA biosynthetic abilities of this new hybrid grouper, we reported the molecular cloning, phylogenetic analysis and nutritional regulation of elovl5, elovl8 and fads2 under different dietary LC-PUFA levels in this fish. 


\section{Materials and Methods}

\subsection{Fish and Sampling}

Juvenile hybrid groupers (4 months old, approximate $20 \mathrm{~g}$ ) were selected in our trial as the first few months of life are the most vulnerable period and crucial for fish growth. They were obtained from a local commercial hatchery (Wenchang, Hainan province, China), and were acclimated in circular tanks at room temperature $\left(28^{\circ} \mathrm{C}\right)$ for two days. The fish were provided a natural photoperiod and adequate dissolved oxygen $\left(>6.0 \mathrm{mg} \mathrm{L}^{-1}\right)$. Four fish were collected and anesthetized with MS-222 (Sigma, St. Louis, MO, USA); then, tissues including liver, heart, intestine, muscle, kidney, stomach, pyloric cease and brain were snap-frozen by liquid nitrogen and then stored at $-80{ }^{\circ} \mathrm{C}$ until use.

\subsection{Gene Cloning}

\subsubsection{Primers Design}

According to the highly conserved domains of the elovl5, elovl8 and fads2 gene sequence obtained by DNAssist software (Version 1.0) from other species, including cobia (Rachycentron canadum), Atlantic salmon, golden pompano (Trachinotus ovatus), orangespotted grouper and giant grouper in the GenBank database (http:/ / www.ncbi.nlm.nih. gov / genbank/ (accessed on 4 January 2022)), specific PCR primers were designed using Primer 5.0 based on the consensus sequences to amplify and confirm the full length of these cDNAs (Table 1) (Figure S1).

Table 1. Primers used for sequencing and qRT-PCR analysis of elovl5, elovl8 and fads 2 from hybrid grouper.

\begin{tabular}{|c|c|c|c|c|}
\hline Primer Name & Sequence $\left(5^{\prime}-3^{\prime}\right)$ & Usage & TM & $\begin{array}{c}\text { Expected } \\
\text { Amplicon } \\
\text { Size }\end{array}$ \\
\hline Elovl5 F & ACCTTCTAATCGTGTGGATG & Partial sequence & $51.9^{\circ} \mathrm{C}$ & \multirow{2}{*}{$648 \mathrm{bp}$} \\
\hline Elov15 R & TGTGCTTCTTGTAAGTCTGA & Partial sequence & $51.3^{\circ} \mathrm{C}$ & \\
\hline Elovl5 5F & AAGCAGTGGTATCAACGCAGAGT & 5'-RACE & $59{ }^{\circ} \mathrm{C}$ & \multirow{3}{*}{$383 \mathrm{bp}$} \\
\hline Elov15 5R & TCCACTTCCTGTGCACTGTGAGTGTC & 5'-RACE & $62.8^{\circ} \mathrm{C}$ & \\
\hline Elovl5 3F & САСАСТСАТСТTССТСТТСТСАААСТТ & $3^{\prime}-\mathrm{RACE}$ & $57.3^{\circ} \mathrm{C}$ & \\
\hline Elov15 3R1 & CTAATACGACTCACTATAGGGCAAGCAGTGGTATCAACGCAGAGT & $3^{\prime}-\mathrm{RACE}$ & $68^{\circ} \mathrm{C}$ & \multirow[t]{2}{*}{$466 \mathrm{bp}$} \\
\hline Elov15 3R2 & CTAATACGACTCACTATAGGGC & 3'-RACE & $51.8^{\circ} \mathrm{C}$ & \\
\hline Elovl8 F & ATGGCTGCTGGTCTACTC & Partial sequence & $53.3^{\circ} \mathrm{C}$ & \multirow{2}{*}{$677 \mathrm{bp}$} \\
\hline Elovl8 R & AGTTACTGAAGAGGATGATGAG & Partial sequence & $51.4{ }^{\circ} \mathrm{C}$ & \\
\hline Elovl8 5F & AAGCAGTGGTATCAACGCAGAGT & 5'-RACE & $59^{\circ} \mathrm{C}$ & \multirow{2}{*}{$608 \mathrm{bp}$} \\
\hline Elovl8 5R & GGTGCCGTGGTGGTAAACATGAAGG & 5'-RACE & $62.5^{\circ} \mathrm{C}$ & \\
\hline Elovl8 3F & ATGCAGAAGTACCTGTGGTGGAAGAGA & $3^{\prime}-\mathrm{RACE}$ & $61.4{ }^{\circ} \mathrm{C}$ & \multirow{3}{*}{$538 \mathrm{bp}$} \\
\hline Elov18 3R1 & CTAATACGACTCACTATAGGGCAAGCAGTGGTATCAACGCAGAGT & 3'-RACE & $68^{\circ} \mathrm{C}$ & \\
\hline Elov18 3R2 & CTAATACGACTCACTATAGGGC & 3'-RACE & $51.8^{\circ} \mathrm{C}$ & \\
\hline Fads2 F & CACTACGCTGGAGAGGATG & Partial sequence & $55.2{ }^{\circ} \mathrm{C}$ & \multirow{2}{*}{608 bp } \\
\hline Fads2 R & TGGTGTTGGTGATGATAGG & Partial sequence & $51.4^{\circ} \mathrm{C}$ & \\
\hline Fads2 5F & AAGCAGTGGTATCAACGCAGAGT & 5'-RACE & $59{ }^{\circ} \mathrm{C}$ & \multirow{3}{*}{$476 \mathrm{bp}$} \\
\hline Fads2 5R & CTCCGTGGCATCCTCTCCAGCGTAGT & $5^{\prime}-\mathrm{RACE}$ & $65.6^{\circ} \mathrm{C}$ & \\
\hline Fads2 3F & CATTTCCAGCATCACGCTAAACCCAAC & 3'-RACE & $60^{\circ} \mathrm{C}$ & \\
\hline Fads2 3R1 & CTAATACGACTCACTATAGGGCAAGCAGTGGTATCAACGCAGAGT & $3^{\prime}-\mathrm{RACE}$ & $68^{\circ} \mathrm{C}$ & \multirow[t]{2}{*}{$1117 \mathrm{bp}$} \\
\hline Fads2 3R2 & CTAATACGACTCACTATAGGGC & 3'-RACE & $51.8^{\circ} \mathrm{C}$ & \\
\hline elongation factor 1 alpha $\mathrm{F}$ & AGGGATGGAAGATTGAGCGC & Internal control & $57.2^{\circ} \mathrm{C}$ & \multirow{2}{*}{$74 \mathrm{bp}$} \\
\hline elongation factor 1 alphaR & CGTACCGGGCTTCAGGATAC & Internal control & $57^{\circ} \mathrm{C}$ & \\
\hline Elovl8 RT-F & CAGATGATCCAGTTCCACGTCA & gRT-PCR & $56.8^{\circ} \mathrm{C}$ & \multirow{2}{*}{$525 \mathrm{bp}$} \\
\hline Elovl8 RT-R & GCGGTAGGTCTGGTAGTAGAAG & qRT-PCR & $56.1^{\circ} \mathrm{C}$ & \\
\hline Elovl5 RT-F & CTACTGCCAGGACACTCACA & qRT-PCR & $56^{\circ} \mathrm{C}$ & \multirow{2}{*}{$415 \mathrm{bp}$} \\
\hline Elov15 RT-R & GAGGCGCCAAAGTATGAGTG & qRT-PCR & $56^{\circ} \mathrm{C}$ & \\
\hline Fads2 RT-F & CCAGGTGGAGGCAGAAGAACA & qRT-PCR & $58.8^{\circ} \mathrm{C}$ & \multirow{2}{*}{184 bp } \\
\hline Fads2 RT-R & AGCCACTATGCTGGAGAGGATG & qRT-PCR & $58.2^{\circ} \mathrm{C}$ & \\
\hline Elovl8 AF & AGCGTGCTCACTCACTTTTAACGG & ORF validation & $57^{\circ} \mathrm{C}$ & \multirow{2}{*}{$933 \mathrm{bp}$} \\
\hline Elovl8 AR & GTGTGCTTCTGCCTTCTCCATCCTT & ORF validation & $59^{\circ} \mathrm{C}$ & \\
\hline Elovl5 AF & GTCGCTTTCTCTCCCCCGCCTCTCA & ORF validation & $64^{\circ} \mathrm{C}$ & \multirow{2}{*}{953 bp } \\
\hline Elovl5 AR & CTACAGTGAGAATTGGGTGGCGGTTT & ORF validation & $60^{\circ} \mathrm{C}$ & \\
\hline Fads2 AF & GCCAAAATCTGGATACTGTGTCAAA & ORF validation & $54^{\circ} \mathrm{C}$ & \multirow{2}{*}{$1628 \mathrm{bp}$} \\
\hline Fads2 AR & AAGACACTGTAAGGCAACCAGAGAAA & ORF validation & $56^{\circ} \mathrm{C}$ & \\
\hline
\end{tabular}

\subsubsection{RNA Extraction and cDNA Synthesis}

Total RNA was extracted from the liver, heart, intestine, muscle, kidney, stomach, pyloric cease and brain using Trizol Reagent (Invitrogen, Waltham, MA, USA) according to the manufacturer's instructions. Quantification of RNA was performed using NanoDrop ND-1000 spectrophotometer (Wilmington, DE, USA), and the quality was measured by 
electrophoresis on a 1.0\% denaturing agarose gel. The RNA $(1 \mu \mathrm{g})$ from all the above tissues was reverse-transcribed into cDNA by PrimeScript ${ }^{\mathrm{TM}}$ RT kit and gDNA Eraser (Perfect Real Time) (Takara, Japan) according to the manufacturer's instructions. To obtain the first partial fragment of gene cloning, RNA $(1 \mu \mathrm{g})$ from liver samples was reverse-transcribed into cDNA using SMARTer®RACE5' /3' kit (Takara, Japan) and GoScript ${ }^{\text {TM }}$ Reverse Transcription System kit (Promega, USA), according to the manufacturer's instructions. The first partial fragment was sequenced by Sangon Biotech Co., Ltd (Shanghai, China), and was verified by NCBI BlastN.

\subsubsection{RACE Amplification}

The $5^{\prime}$ and $3^{\prime}$ rapid amplification of cDNA ends (RACE) PCR template were obtained according to the manufacturer's instructions (SMARTer ${ }^{\mathrm{TM}}$ RACE cDNA Amplification Kit, Clontech, San Jose, CA USA). For $3^{\prime}$ and $5^{\prime}$ RACE of elovl8, gene-specific primers, Elovl8-3F and Elovl8-5R, and Universal Primer (provided in the kit) were used in gradient PCR. Amplification was performed in a total volume of $20 \mu \mathrm{L}$, containing $10 \mu \mathrm{L} 2 \times$ Taq PCR Master Mix II, $0.5 \mu \mathrm{L}$ of each primer $(10 \mu \mathrm{M}), 7 \mu \mathrm{L}$ nuclease-free water, and $2 \mu \mathrm{L} c D N A$ (50 ng $/ \mu \mathrm{L}$ ). For $3^{\prime}$ and 5' RACE of elovl5, Elov15-3F and Elov15-5R, and Universal Primer were used in gradient PCR. For $3^{\prime}$ and $5^{\prime}$ RACE of fads2, Fads2-3F1 and Fads2-5R1, and Universal Primer were used in gradient PCR. The PCR product was purified, cloned into a pMD19-T vector (Takara, Japan), then transformed and sequenced. The full lengths of the grouper elovl5, elovl8 and fads2 cDNA were obtained by aligning the first partial sequence with the corresponding RACE PCR products using DNAssist software (Version 1.0). The cloned PCR fragments were then sequenced by Sangon Biotech Co. Ltd. (Shanghai, China).

\subsubsection{Sequence and Phylogenetic Analysis}

The nucleotide sequence and the amino acid sequence of Elov15, Elov18 and Fads2 were analyzed by the NCBI blast program (http:/ / www.ncbi.nlm.nih.gov/blast/Blast. cgi (accessed on 4 January 2022)). The conserved domains of Elov15, Elov18, and Fads2 sequences were predicted by the SMART and CDD programs. The molecular weight, isoelectric point, and amino acid content were identified by online software ExPASy (http: / / web.expasy.org/protparam/ (accessed on 4 January 2022)). The Elov15, Elovl8 and Fads2 amino acids' multiple sequence alignments were found using the CLUSTALX software (Version 1.8.1). The sequences alignment of Elovl4, Elovl5 and Elovl8 were uploaded into MEGA 10.0 and all columns containing 75\% gaps were stripped from the alignment, leaving a total of 232 positions for phylogenetic analysis. The sequences alignment of Fads2 were uploaded into MEGA 10.0 and all columns containing 4.3\% gaps were stripped from the alignment, leaving a total of 438 positions for phylogenetic analysis. The evolutionary model was determined using the MODELS option in MEGA 10.0 resulting in a LG + G, and branch support was calculated using maximum likelihood (Figure S2). The number of booststrap replications for phylogeny test are 1000.2.2. Feeding trial with different n-3 LC-PUFA levels

Three isoenergetic (339 kcal/100 g), isonitrogenous (53\%) and isolipidic (7\%) experimental diets (Table 2) were formulated containing graded levels of n-3 LC-PUFA (0.53\%, $1.19 \%$ and $2.69 \%$ ) based on our previous study (Table 3) (Figure S3). Juvenile hybrid groupers were obtained from a local commercial hatchery (Wenchang, Hainan province, China). Fish were acclimated with commercial diets for 2 weeks before the experiment. A total of 108 fish (average initial weight, $20.8 \pm 0.03 \mathrm{~g}$ ) were selected and randomly distributed into 9 glass tanks ( $60 \mathrm{~cm} \times \mathrm{W} 45 \mathrm{~cm} \times \mathrm{H} 50 \mathrm{~cm}$ ) connected to a water-recycling system. The water was oxygenated through air stones at the bottom of each tank. Triplicate groups of fish were fed to apparent satiation by hand twice daily (8:00 am and 4:30 pm). Water temperature $\left(29 \pm 0.5^{\circ} \mathrm{C}\right)$, total ammonia $(0-0.15 \mathrm{mg} / \mathrm{L})$ and dissolved oxygen $(5.9 \pm 0.1 \mathrm{mg} / \mathrm{L})$ were monitored daily. Fish were exposed to a $12 \mathrm{~h}: 12 \mathrm{~h}$ light: dark cycle. The feeding trial lasted 42 days. At the end of the experiment, fish were counted and weighed after being subjected to $16 \mathrm{~h}$ fasting. Two fish per tank were randomly collected 
and anesthetized with MS-222 at $80 \mathrm{mg} \mathrm{L}^{-1}$ (Sigma, St. Louis, MO, USA): Liver was sampled and snap-frozen by liquid nitrogen and then stored at $-80^{\circ} \mathrm{C}$ for the RNA extraction.

Table 2. Formulation and proximate analysis of the experimental diets.

\begin{tabular}{cccc}
\hline Ingredients (g/100 g $_{\text {Diet) }}$ & \multicolumn{3}{c}{ Dietary $\mathbf{n - 3 ~ P U F A ~ L e v e l s ~}$} \\
\cline { 2 - 4 } & $\mathbf{0 . 5 3}$ & $\mathbf{1 . 1 9}$ & $\mathbf{2 . 6 9}$ \\
\hline Fish meal $^{1}$ & 22 & 22 & 22 \\
Pork blood meal $^{2}$ & 6.0 & 6.0 & 6.0 \\
Chicken meal $^{3}$ & 18 & 18 & 18 \\
Casein $^{4}$ & 17.5 & 17.5 & 17.5 \\
Palm oil $^{5}$ & 3.41 & 2.53 & 0.66 \\
DHA purified oil $^{6}$ & 0.2 & 0.73 & 1.87 \\
EPA purified oil $^{7}$ & 0 & 0.35 & 1.08 \\
Vitamin premix $^{8}$ & 1 & 1 & 1 \\
Mineral Premix $^{9}$ & 0.5 & 0.5 & 0.5 \\
Starch $_{\text {Cellulose }}$ & 16 & 16 & 16 \\
Crude protein $_{\text {Crude lipid }}$ & 13.4 & 13.4 & 53.4 \\
n-3 PUFA & 53.3 & 53.4 & 7.1 \\
\end{tabular}

${ }^{1}$ Yongsheng Feed Co., Ltd (Binzhou, Zhejiang province, China). Proximate composition (\%Dry matter): Moisture, 7.43; Crude protein, 73.3; Crude lipid, $5.1{ }^{2}$ Zhejiang Sonak Company (Chaozhou, Zhejiang province, China) Proximate composition (\%Dry matter): Moisture, 6.46; Crude protein, 98.53; Crude lipid, 0.02; ${ }^{3}$ Dalian Xin Ruisen Trading Company (Dalian, Liaoning province, China). Proximate composition (\%Dry matter): Moisture, 4.38, Crude protein, 68.77; Crude lipid, 12.6; ${ }^{4}$ Gansu Hualing Dairy Products Co., Ltd (Hezuo, Gansu province, China). Proximate composition (\%Dry matter): Moisture, 4.38; Crude protein, $93.80 ;{ }^{5}$ Tianjin Julong Cereals and Oils Co., Ltd (Tianjin, China).; ${ }^{6}$ Shaanxi Guanchen Biological Co., Ltd (Xian, Shaanxi province, China). Proximate composition (\%Dry matter): Dh 75.1; EPA 4.8; ${ }^{7}$ Shaanxi Guanchen Biological Co., Ltd (Xian, Shaanxi province, China). Proximate composition (\%Dry matter): DHA 5.1; EPA $74.9 ;{ }^{8}$ Vitamin premix (mg/g premix): thiamin hydrochloride, 2.5; riboflavin, 10; calcium pantothenate, 25; nicotinic acid, 37.5; pyridoxine hydrochloride, 2.5; folic acid, 0.75; inositol, 100; ascorbic acid, 50; choline chloride, 250; menadione, 2; alpha-tocopheryl acetate, 20; retinol acetate, 1; cholecalciferol, 0.0025; biotin, 0.25; vitamin B12, 0.05. All ingredients were supplemented to $1 \mathrm{~g}$ with alpha cellulose; ${ }^{9}$ Mineral Premix (mg/g mixture): calcium lactate, $327 ; \mathrm{K}_{2} \mathrm{PO}_{4}, 239.8 ; \mathrm{CaHPO}_{4} \cdot 2 \mathrm{H}_{2} \mathrm{O}$, 135.8; $\mathrm{MgSO}_{4} \cdot 7 \mathrm{H}_{2} \mathrm{O}, 132 ; \mathrm{Na}_{2} \mathrm{HPO}_{4} \cdot 2 \mathrm{H}_{2} \mathrm{O}, 87.2 ; \mathrm{NaCl}$, 43.5; ferric citrate, $29.7 ; \mathrm{ZnSO}_{4} \cdot 7 \mathrm{H}_{2} \mathrm{O}, 3 ; \mathrm{CoCl}_{2} \cdot 6 \mathrm{H}_{2} \mathrm{O}, 1$; $\mathrm{MnSO}_{4} \cdot \mathrm{H}_{2} \mathrm{O}, 0.8 ; \mathrm{KI}, 0.15 ; \mathrm{AlCl}_{3} \cdot 6 \mathrm{H}_{2} \mathrm{O}, 0.15 ; \mathrm{CuCl}_{2}, 0.1 ;$ Note: The data represent the average of repeated samples.

Table 3. Fatty acid composition of experimental diets. The results are expressed as the average of repeated samples; SFA: saturated fatty acid; MUFA: monounsaturated fatty acid; PUFA: highly unsaturated fatty acid.

\begin{tabular}{cccc}
\hline \multirow{2}{*}{ Fatty Acid } & \multicolumn{3}{c}{ Dietary n-3 PUFA Levels } \\
\cline { 2 - 4 } & $\mathbf{0 . 5 3}$ & $\mathbf{1 . 1 9}$ & $\mathbf{2 . 6 9}$ \\
\hline $14: 0$ & 1.01 & 1.27 & 2.04 \\
$16: 0$ & 28.18 & 23.55 & 10.16 \\
$18: 0$ & 10.26 & 8.75 & 9.40 \\
$16: 1 \mathrm{n}-9$ & 0.97 & 2.12 & 3.18 \\
$18: 1 \mathrm{n}-7$ & 0.80 & 0.87 & 0.91 \\
$18: 1 \mathrm{n}-9$ & 20.75 & 17.33 & 19.48 \\
$20: 1 \mathrm{n}-9$ & 0.11 & 0.11 & 0.21 \\
$22: 1 \mathrm{n}-9$ & 0.11 & 0.10 & 0.10 \\
$18: 2 \mathrm{n}-6$ (LA) & 18.13 & 13.06 & 5.99 \\
$18: 3 \mathrm{n}-6$ & 0.41 & 0.32 & 0.30 \\
$20: 2 \mathrm{n}-6$ & 0.10 & 0.20 & 0.31 \\
$20: 4 \mathrm{n}-6$ (ARA) & 1.06 & 1.07 & 0.99 \\
$18: 3 \mathrm{n}-3$ (ALA) & 1.07 & 1.00 & 1.01 \\
$20: 5 n-3$ (EPA) & 2.99 & 6.69 & 15.12 \\
$22: 6 n-3$ (DHA) & 4.61 & 10.28 & 23.29 \\
$\sum$ SFA & 39.45 & 33.57 & 21.60 \\
$\sum$ MUFA & 22.73 & 20.54 & 23.87 \\
En-3 PUFA & 7.60 & 16.97 & 38.41 \\
\hline
\end{tabular}




\subsection{Quantitative Real-Time PCR}

RT-PCR was carried out in a quantitative thermal cycler (Roche Light Cycler®480, Switzerland). The amplification was performed in a total volume of $20 \mu \mathrm{L}$ containing $10 \mu \mathrm{L}$ power SYBR $®$ Green PCR Master Mix (Takara, Japan), $0.8 \mu \mathrm{L}$ of each primer $(10 \mu \mathrm{M}), 6.4 \mu \mathrm{L}$ nuclease-free water and $2 \mu \mathrm{L}$ of cDNA $(50 \mathrm{ng} / \mu \mathrm{L})$. The real-time RT-PCR program was as follows: $95^{\circ} \mathrm{C}$ for $30 \mathrm{~s}$, followed by 40 cycles of $95^{\circ} \mathrm{C}$ for $5 \mathrm{~s}, 60^{\circ} \mathrm{C}$ for $20 \mathrm{~s}$, and $65^{\circ} \mathrm{C}$ for $15 \mathrm{~s}$. After the amplification phase, a melt curve of $0.5^{\circ} \mathrm{C}$ increments from $65^{\circ} \mathrm{C}$ to $90^{\circ} \mathrm{C}$ was performed, enabling the confirmation of the amplification of a single product in each reaction for the melting curve. Standard curves were made with five different dilutions (in triplicate) of the cDNA samples and the amplification efficiency was analyzed according to the following equation $\mathrm{E}=10^{(-1 / \text { slope })}-1$. Real-time PCR efficiencies of elovl8, elovl5, fads2 and elongation factor 1 (ef1alpha) ranged between $96.2 \%$ and $104.7 \%, 96.5 \%$ and $105.5 \%$, $97.1 \%$ and $106.1 \%, 95.6 \%$ and $106.2 \%$, respectively. Ef1alpha was used as the housekeeping gene to normalize of the results (as our previous study). The expression levels of the target genes were calculated followed by the $2-{ }^{\Delta \Delta \mathrm{Ct}}$ method.

\subsection{Statistical Analysis}

The normality and homogeneity of the data were explored using Hartley's test. Then, data were subjected to one-way analysis of variance (ANOVA) and Duncan's multiple range test (SPSS 22.0 for Windows, Chicago IL, USA) to determine if significant differences occurred between different treatments. Differences were considered significant at $p<0.05$. All data are presented as mean \pm S.E.M.

\section{Results}

\subsection{Gene Cloning and Sequence Analysis of elovl5, elovl8 and fads2}

The cloned elovl5 cDNA from the hybrid grouper (uploaded under GenBank Accession Number MZ713365) was $1226 \mathrm{bp}$, which contained an $885 \mathrm{bp}$ ORF that encoded a polypeptide of 294 amino acids, a $41 \mathrm{bp} \mathrm{5} 5^{\prime}$ UTR and a $300 \mathrm{bp} \mathrm{3'}$ UTR (Figure S4). The hybrid grouper Elov15 protein has a calculated molecular mass of $35.10 \mathrm{kDa}$ and an isoelectric point of 9.25 amino acid sequence deduced by SMART analysis, which has 7 transmembrane domain located at residues 32-50, 63-85, 111-132, 139-161, 176-198, 205-227 and 231-250 respectively, a highly conserved redox center histidine cluster (143-147), 3 conserved motifs (120-127, 173-184 and 203-209), and an endoplasmic reticulum retention signal (288-294). The NCBI-CDD program showed that Elovl5 included a conservative region of LC-PUFA elongases located at residues 28-256.

The cloned elovl8 cDNA from a hybrid grouper (uploaded GenBank Accession Number MZ713364) was $1228 \mathrm{bp}$, which contained a $792 \mathrm{bp}$ ORF that encoded a polypeptide of 263 amino acids with a $111 \mathrm{bp} 5^{\prime}$ UTR and a $325 \mathrm{bp} 3^{\prime}$ UTR (Figure S5). The encoded Elovl8 protein has a calculated molecular mass of $30.8 \mathrm{kDa}$ and an isoelectric point of 9.21 amino acid sequence, deduced by SMART analysis. Meanwhile, the Elovl8 protein possessed 7 transmembrane domains located at residues 25-50, 63-85, 111-113, 140-159, 169-191, 203225 and 105-127, respectively, a highly conserved redox center histidine cluster (259-263), 4 conserved motifs (121-128, 139-148, 174-185 and 205-211), and an endoplasmic reticulum retention signal (259-263). The NCBI-CDD program showed that the newly cloned Elov18 possessed a conservative region of LC-PUFA elongases located at residues 28-262.

The cloned fads2 cDNA from the hybrid grouper (uploaded under GenBank Accession Number MZ713366) was 2006 bp, which contained a 1338 bp ORF that encoded a polypeptide of 445 amino acids, a $238 \mathrm{bp} 5^{\prime}$ UTR and a $430 \mathrm{bp} 3^{\prime}$ UTR (Figure S6). The encoded Fads2 protein has a calculated molecular mass of $52.04 \mathrm{kDa}$ and isoelectric point of 8.41 amino acid sequence deduced by SMART analysis, which had 3 transmembrane domain located at residues 148-170, 267-289 and 304-326, respectively, 3 highly conserved redox center histidine cluster (181-185, 218-222 and 383-387), 3 conserved motifs (120-127, 173-184 and 203-209), and an N-terminal Cyt-b5 domain with typical heme-binding motif 
(288-294). The NCBI-CDD program showed that Fad2 included a conservative region located at residues 163-413.

\subsection{Multiple Sequence Alignment and Phylogenetic Analysis}

A multiple sequence alignment and phylogenetic analysis were conducted to investigate the homology of genes elovl5, elovl8 and fads2 between hybrid grouper and other species. The results showed that most of the amino acid residues in fish, including hybrid grouper, were highly aligned with Elovl5 and Elovl8 (Figures 1 and 2). They possessed all the characteristic features of Elovl family members, including multiple transmembrane regions, a single-histidine dideoxy-binding motif $\mathrm{HXXHH}$, the putative endoplasmic reticulum (ER) retrieval signal KKKQK and KKLRVD, respectively, at the carboxyl terminus and multiple regions, containing similar motifs, such as (1) KXXEXXDT, (2) QXXFLHXXHH, (3) NXXXHXXMYXYY, (4) and TXXQXXQ.Fads2 possessed all the characteristic features of Fads family members, including multiple transmembrane regions, and three singlehistidine dideoxy-binding motifs: $\mathrm{HXXHH}, \mathrm{HDXGH}$ and QXXHH (Figure 3).

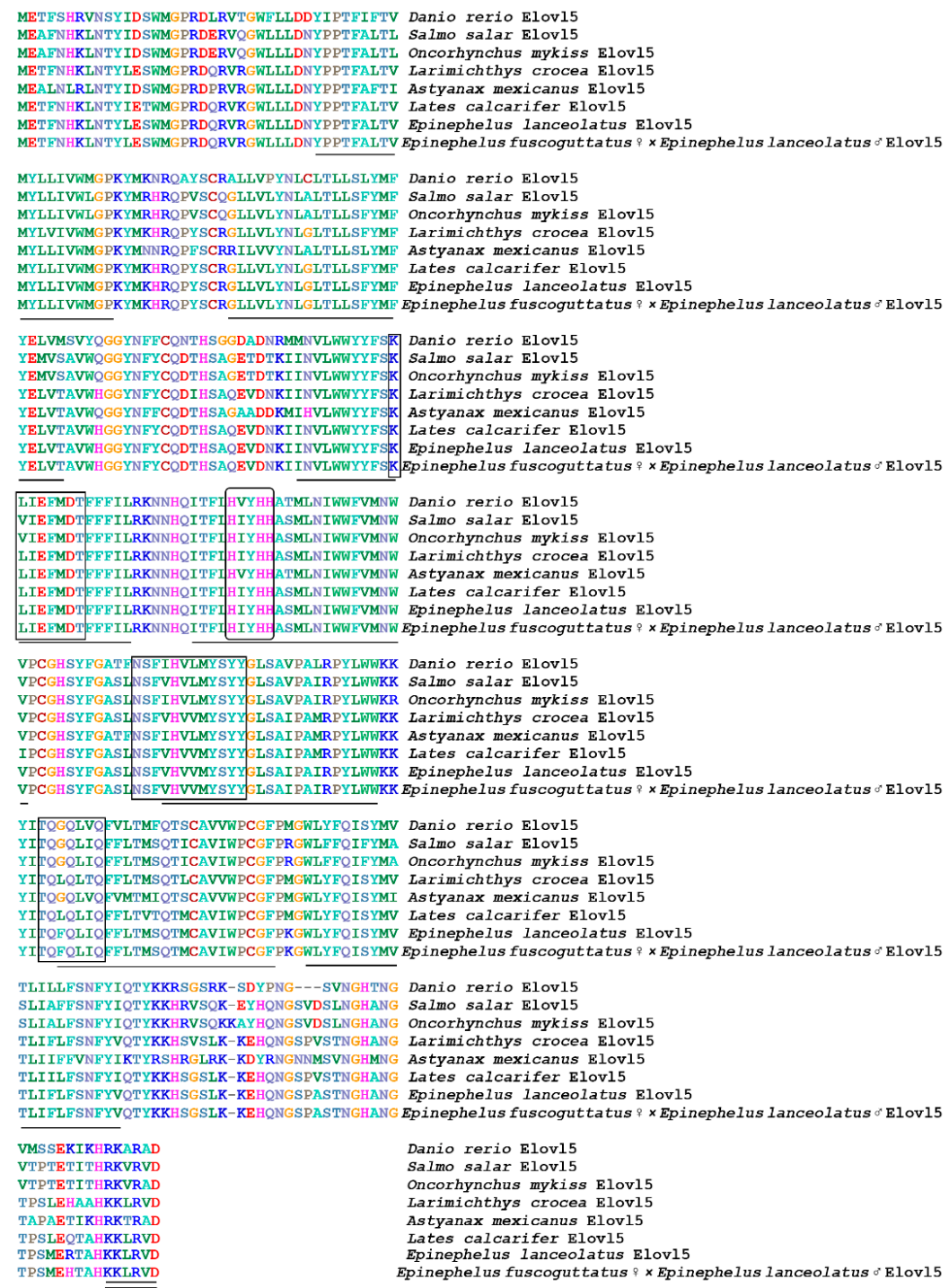

Figure 1. Multiple amino acids sequence alignment of Elovl5 from different fish species. The transmembrane region of amino acids is represented by a straight line; the conserved motif is marked with a square; the histidine box is marked with an ellipse, and endoplasmic reticulum signal is marked with a double line. 
Phylogenetic analysis by the maximum likelihood method showed three clusters for elov18, elov14 and elov15, with elov18 cluster showing closest relationship to the elov14 cluster (Figure 4). Amino acid sequence of hybrid grouper Elovl8 exhibited high identity with Siganus_canaliculatus Elovl8b (86\%), Salmo salar Elovl8b (83\%) and Danio rerio Elovl8b (80\%). Elov15 was closest to Perciformes, such as Epinephelus coioides (99\%), Epinephelus lanceolatus (99\%), Acanthopagrus schlegelii (95\%) and Larimichthys crocea (95\%).

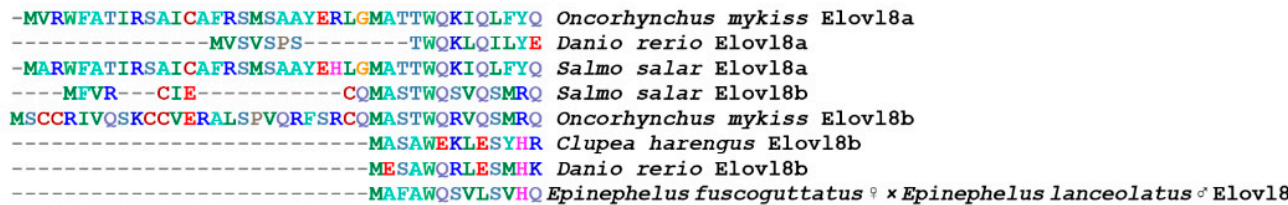

GVLDNGDKRTDSWLLVYSPVPITCIFLCYLLLIWVGPKLM Oncorhynchus mykiss Elov18a

RILENGDKRTD GWLLVYSPLPVGGIFLCYLVMVWFGPKLM Danio rerio Elovl8a

GVLDNGDKRTDSWLLVYSPVPITCIFLCYLLLIWVVPKLM Salmo salar Elovl8a

WILENGDKRTD PWLLVYSPMPVAFIFLLYLGVVWAGPKLM Salmo salar Elov18b

WILENGDKRTD PWLLVYSPMPVAIIFLLYLGVVWAGPKLM Oncorhynchus mykiss Elov18b

WIFENGDKRTDPWLLVYSPVPVICIFLSYLGVIWIGPKLM Clupea harengus Elov18b

WIVENGDKRTDPWLLVYSPVPIICIFLCYLGVIWIGPKLM Danio rerio Elovl8b

RIVDNGDKRTDPWLLVYSPVPVALIFLVYLCVVWAGPRLM Epinephelus fuscoguttatus 9 Epinephelus lanceolatus ${ }^{\circ}$ Elovl8

AOROPVNLKPVLIIYNFAMVCLSAYMFYEFTASSWLANYS Oncorhynchus mykiss Elovl8a

VHREPVNIOALLIIYNFSMVCLSAYMFYEFTVSSWLASYS Danio rerio Elov18a

AOROPVNLKPVLIIYNFAMVCLSAYMFYEFTASSWLANYS Salmo salar Elov18a

KRREPVDLKAVLIVYNFAMVCLSVYMFHEFLVTSLLSNYS Salmo salar Elovl8b

KRREPVDLKAVLIVYNFAMVCLSVYMFHEFLVTSLLSNYS Oncorhynchus mykiss Elovl8b

KHREPVDLKVVLIVYNFAMVLLSVYMFHEFVMASWLANYS Clupea harengus Elov18b

KNMEPVNLKGLLIVYNF SMV GLSVYMFHEFLVTSWLANYS Danio rerio Elovl8b

KHREPVDLKVVLIVYNFAMVGLSAYMCYEFLVTSWLSSYS Epinephelus fuscoguttatus 9 × Epinephelus lanceolatus $0^{\prime}$ Elovl8

ILCQPVDYNTSPLAMRMAKVCWWFYFSKVIELSDPLFFIL Oncorhynchus mykiss Elovl8a

LLCOPVDYTENPL PMRMARVCWWFYFSKVIELADTMFFIL Danio rerio Elovl8a

ILCOPVDYNTS PLAMRMAKVCWWFYFSKVIELSD PLFFIL Salmo salar Elov18a

YLCOPVDYSTSPLAMRMAKVCWWFFFSKVIELADPVFFIL Salmo salar Elovl8b

YLCQPVDYSTSPLAMRMAKVCWWFFF SKIELAD PVFFIL Oncorhynchus mykiss Elovl8b

YLCQPVDYSTSPLAMRMASAVWWFFFSKVIELSDIVFFIL Clupea harengus Elovl8b

YLCQPVDYSTSPLGMRMANVCWWFFF SVIELSDPVFFIL Danio rerio Elovl8b

LLCQPVDYSTNPLALRMARVCWWFF SKVIELSDFIFFIL Epinephelus fuscoguttatus 9 × Epinephelus lanceolatus $0^{*}$ Elovl8

RKKNSQLTFIFVYHA PTMIFNWWAGKYVAGGQSFLIGLI Oncorhynchus mykiss Elovl8a

RKKNN LLTFIHVYHH ETMIFNWWAGVKYVAGGQSFLIGLI Danio rerio Elovl8a

RKKNSOLTFT HVYHH ETMI FNWWAGVKYVAGGOSFLI LI Salmo salar ElOVl8a

RKKNSOTET

RKKNSLLTFI HVYHH ETMIFNWWAGVKYLAGGOSFFIGLL Oncorhynchus mykiss Elovl8b

RKKNSPLTF

\begin{tabular}{l|l} 
RKKNN LLTFI HVYHH TMI FNWWAGVKYLAGGQSFFIGVL Clupea harengus Elov \\
RKKNSOLTFL HVYHH
\end{tabular}

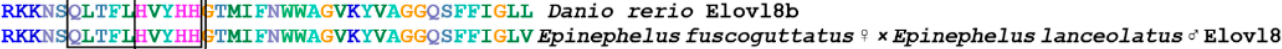

NSLVHVVMYLYY LAALGPHMQQYLWWKRYITSLQLLQFE Oncorhynchus mykiss Elov18a

NSFVHVVMYMYY LAALGPQMQKYLWWKRYITSLQLLOFF Danio rerio Elovl8a

NSLVHVVMYLYY LLAALGPHMOOYLWWKRYTSLOLLOFF Salmo salar Elov18a

NTFVHIVMYSYY LLAALGPHTOKYLWWKRYITSLOLIO FV Salmo salar ElOvl8b

NTFVH IVMY SYY LAALGPHTOKYLWWKRYITSLQLLOEV Oncorhynchus mykiss Elovl8b

NPFVHTVMYSYY LAALGPHMOKYLWWKRYITSLOLLOFV Clupea harengus Elov18b

NTFVHIWMYSYY LAALGPHLQKYLWWKRYITSLQLVQ I Danio rerio Elov18b

NTFVHIVMY YY LAAL GPHMOKYLWWRYITSLLLV FV Epinephelus fuscoguttatus 9 Epinephelus lanceolatus ${ }^{\circ}$ Elov18

IVTIHTSYNLFTDCDFPDSMNAVVFAYSLSLIVLFRNFYY Oncorhynchus mykiss Elovl8a

IVTIHTAFNLYADCDFPDSMNMVLGYALSLIALFSNFYY Danio rerio Elov18a

IVTIHTSYNLFTDCDFPDSMNTVVVYSLSLIVLFRNFYY Salmo salar Elov18a

LLTTHTGYNLFTECDFPDSMNAVVFAYCVSLIALFSNFYY Salmo salar Elovl8b

LLTTHTGYNLFTECDFPDSMNAVVFAYCVSLIALFSNFYY Oncorhynchus mykiss Elovl8b

LLTIHTAYNLFADCDFPDTMNTFVFAYLLSLIALFSNFYY Clupea harengus Elov18b

LLTVHTGYNLFTECEFPDSMNAVVFAYCVSLIILFSNFYY Danio rerio Elovl8b

LFLLHTGYNLFTECDFPDSMNVVFGYCVTLIILFSNFYF Epinephelus fuscoguttatus $\circ$ Epinephelus lanceolatus $0^{\circ}$ Elovl8

QSYLTKKSKOT

QSYLSKKTKL.

QSYLTKKSKQT

QSYLNRKSKKT

QSYLNRKSKKT

QSYVNRKSKKL

QSYIKRKSKKS

QSYLNKKKOK

Oncorhynchus mykiss Elovl8a

Danio rerio Elovl8a

Salmo salar Elovi8a

Salmo salar Elovl8b

Oncorhynchus mykiss Elovl8b

Clupea harengus Elovl8b

Danio rerio Elovl8b

Epinephelus fuscoguttatus 9 Epinephelus lanceolatus ${ }^{\circ}$ Elovl

Figure 2. Multiple amino acids sequence alignment of Elovl8 from different species. The transmembrane region of amino acids is represented by a straight line; the conserved motif is marked with a square; the histidine box is marked with an ellipse, and endoplasmic reticulum signal is marked with a double line. 


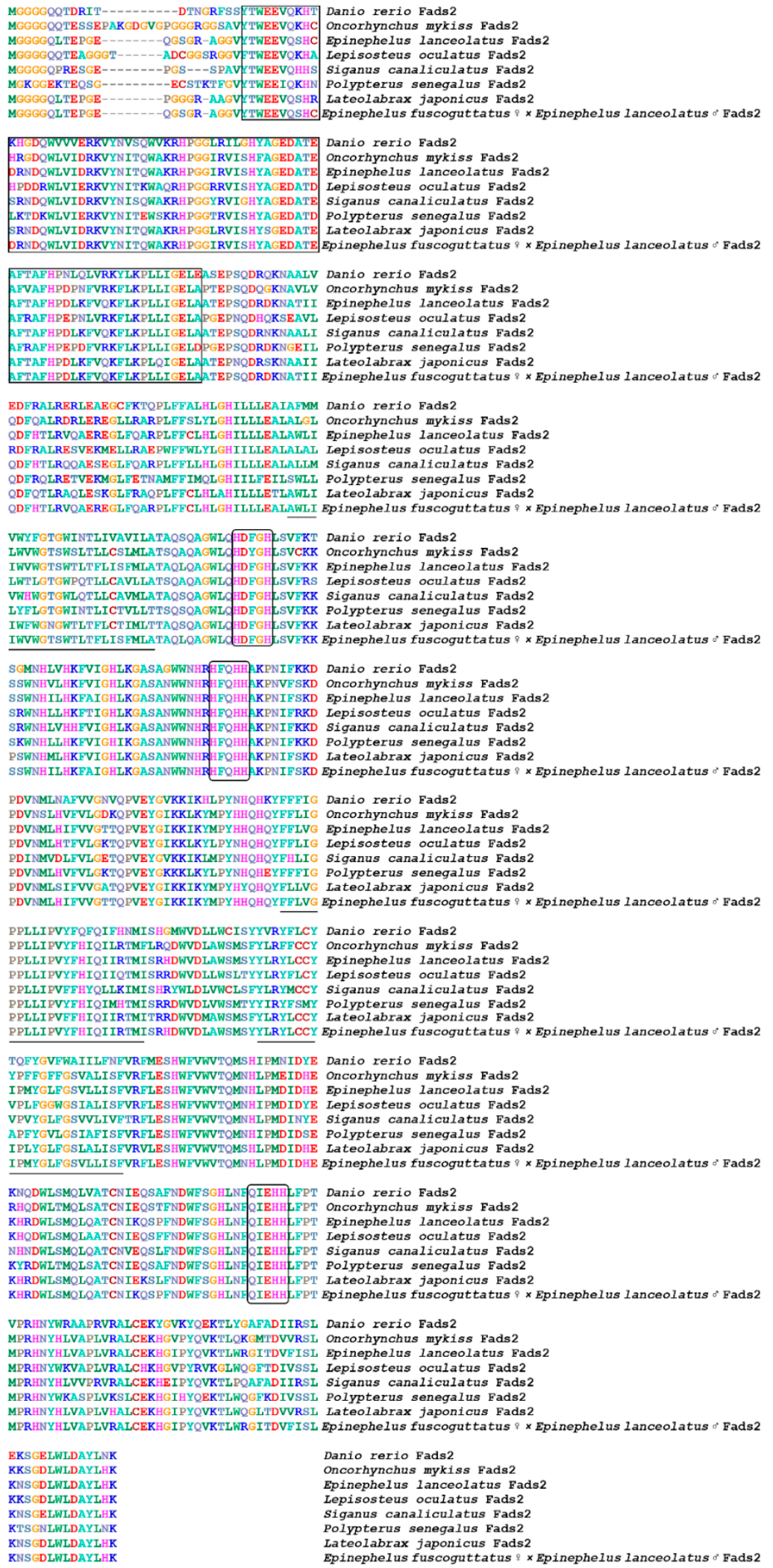

Figure 3. Multiple amino acids sequence alignment of Fads2 from different species. The transmembrane region of amino acids is represented by a straight line; the conserved motif is marked with a square; the histidine box is marked with an ellipse, and endoplasmic reticulum signal is marked with a double line. 


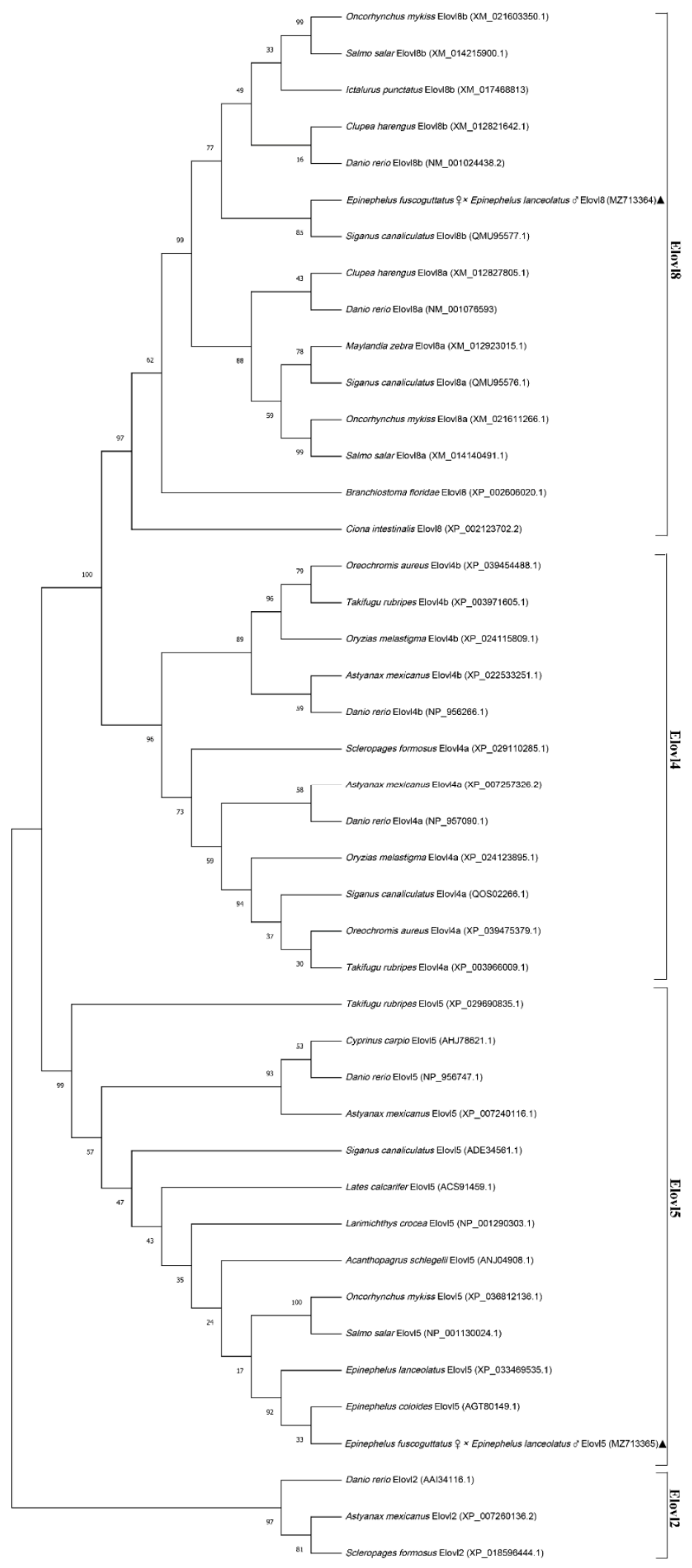

Figure 4. Phylogenetic tree analysis constructed by using the full-length amino acid sequences of Elov18, Elovl4 and Elov15. The full-length amino acid sequence of Elovl8, Elovl4 and Elov15 proteins were extracted from Genbank and analyzed using the maximum likelihood method by Mega $x$ with 1000 bootstrap replications. Elovl2 is regarded as the outgroup. The numbers shown at branches indicated the bootstrap values (\%). Our Epinephelus fuscoguttatus $+\times$ Epinephelus lanceolatus $\sigma^{\top}$ sequence was marked " $\boldsymbol{\Lambda}$ ". 
Phylogenetic analysis of Fads2 showed that the hybrid grouper clustered in the Fads2 group rather than Fads1 (Figure 5). Moreover, Fads2 in hybrid grouper shared high sequence identity with Fads2 of Perciformes, such as Epinephelus coioides (99\%), Epinephelus lanceolatus (99\%), Lateolabrax japonicus (88\%), Larimichthys crocea $(82 \%)$, and Lepisosteus oculatus (74\%) and less similar to Fads1 such as Anguilla japonica (60\%), Polypterus senegalus (59\%) and Lepisosteus oculatus (56\%).

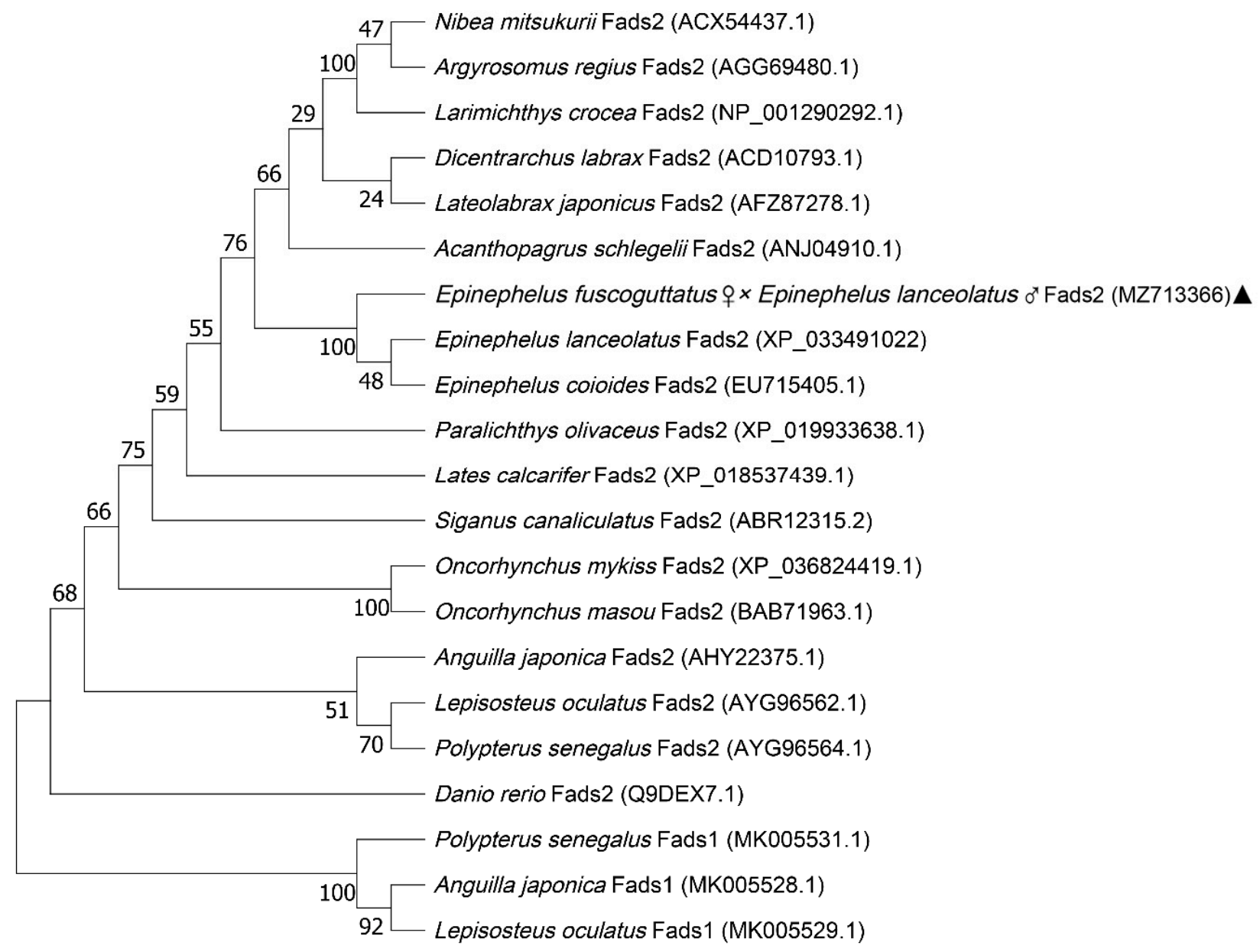

Figure 5. Phylogenetic tree analysis constructed by using full-length amino acid sequences of Fads2. The full-length amino acid sequence of Fads2 and Fads1 proteins were extracted from Genbank and analyzed using Maximum Likelihood method by Mega x with 1000 bootstrap replications. The numbers shown at branches indicated the bootstrap values (\%). Fads1 is regarded as the outgroup.

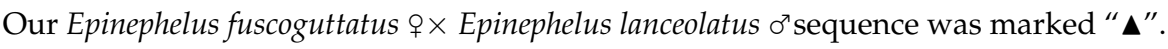

\subsection{Tissue Distribution of elovl5, elovl8 and fads2 mRNA Hybrid Grouper}

As shown in Figure 6, the elovl5, elovl8 and fads2 genes were widely expressed in all the detected tissues of the hybrid grouper, including intestine, liver, muscle, brain, kidney, stomach, heart and pyloric caeca, with the highest expression in the brain $(p<0.05)$. Furthermore, moderate expression of elovl5 and elovls genes was found in the liver and stomach, while the fads 2 gene most highly expressed in liver and muscle. The results also showed that the heart and kidney were the tissues with the lowest gene expression of elovl5 and fads2 $(p<0.05)$, while the lowest value for elovl8 gene expression was found in the kidney $(p<0.05)$. 

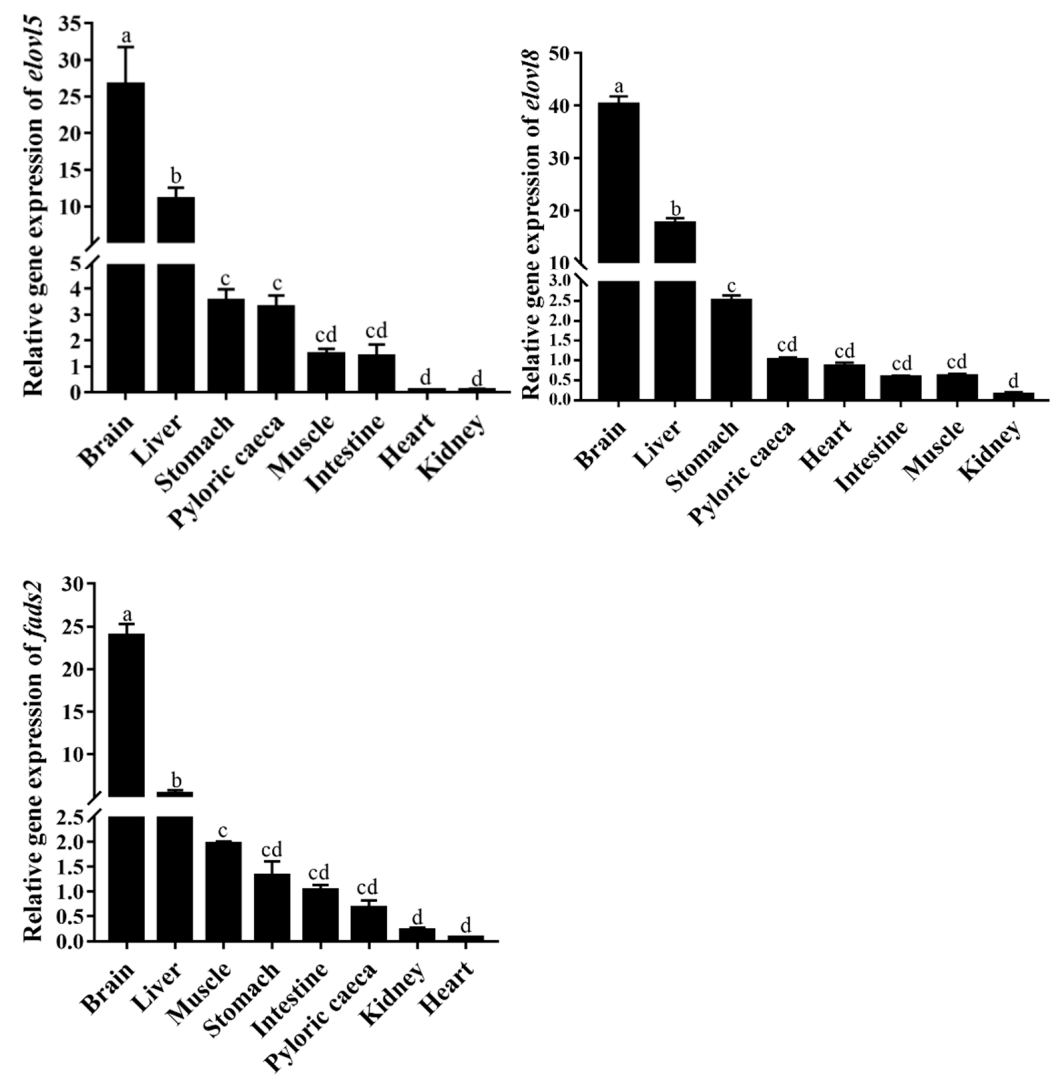

Figure 6. Tissue expression of elovl5, elovl8 and fads2 genes in hybrid grouper. Results are expressed as mean standard error $(n=4)$. Different letters above the bars denote significant $(p<0.05)$ differences among tissues.

\subsection{Nutritional Regulation of Hybrid Grouper elovl5, elovl8 and fads2 Genes Expression}

The gene expression of elovl8, elovl5 and fads 2 in the liver of hybrid grouper were significantly affected by the dietary n-3 LC-PUFA levels $(p<0.05)$ (Figure 7). Elovl5 and elovl8 relative mRNA expressions were significantly decreased at 1.19 and 2.69 of dietary n-3 LC-PUFA levels compared with group $0.53(p<0.05)$. In contrast, a significantly downregulated gene expression of fads 2 was recorded in group 2.69 compared with other treatments $(p<0.05)$.

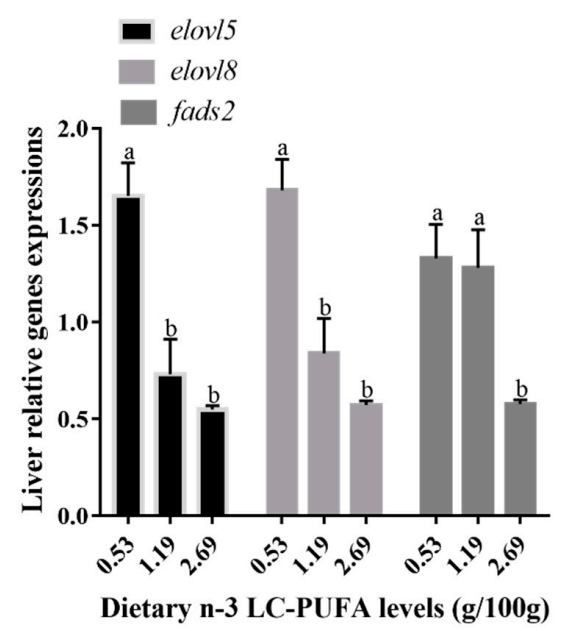

Figure 7. Relative mRNA expression of elovl5, elovl8 and fads 2 in liver of hybrid grouper fed diets with different levels of $n-3$ LC-PUFA. Results are expressed as means standard error $(n=3)$. Different letters above the bars denote significant $(p<0.05)$ differences among dietary groups. 


\section{Discussion}

Similar to other cultured marine fish species, fish oil is the primary lipid source for hybrid groupers. Considering the non-sustainable reliance on fish oil to farm this species, several trials have investigated the impact of the dietary replacement of fish oil with alternatives [30-33]. However, studies related to the molecular basis of LC-PUFA biosynthesis and regulation, which could optimize the pathway to the efficient use of alternatives, are still limited in hybrid groupers. Thus, we first cloned and characterized the main enzymes participating in the LC-PUFA biosynthesis in the present study, including Elov15, Elov18 and Fads2, from this fish species. To date, elovl5 cDNA has been identified in numerous marine fish species, including Epinephelinae, and has been demonstrated to effectively elongate C18 and C20 PUFA [34]. In the present study, the isolated hybrid grouper elovl5 cDNA sequence had 294 amino acids and showed high identity with other teleost elovl5, particularly Perciformes including Epinephelus coioides (99\%), Epinephelus lanceolatus (99\%), Acanthopagrus schlegelii (95\%) and Larimichthys crocea (95\%). The hybrid grouper Elovl5 possessed standard features for Elovl protein family members, including the so-called histidine box (HXXHH), the canonical C-terminal ER retention signal, several predicted transmembrane regions and other highly conserved motifs [35].

Elovl8a and elovl8b were first identified and functionally characterizated in rabbitfish from Li's lab. Multiple sequences alignment showed that elovl8 shared a closer relationship with elovl4 [18]. Afterwards, Sun et al. conducted a phylogenetic analysis to establish the orthology of the newly identified elovls gene and revealed that the similar orthologs from some fish species which were all annotated as elovl4 or elovl4-like could be misidentified due to the sequence similarity to elovl4 genes [9]. Thus, the previously similar elovl genes that have been annotated as "elovl4" (or "elovl4-like") in many fish species were considered to be elovl8 [9]. Similarly, amino acid sequence alignment with elovl4, elovl5 and elovl8 from other species showed that the new isolated "elovl4" gene from hybrid grouper was highly similar to those of elovl8b, and exhibited high identity with other teleost elovl8b, particularly Perciformes, including Siganus canaliculatus Elovl8b (86\%), Salmo salar Elovl8b (83\%), Oncorhynchus mykiss Elovl8b (83\%), Ictalurus punctatus Elovl8b (81\%) and Danio rerio Elovl8b $(80 \%)$. Hybrid grouper Elovl8 possessed all the features of Elovl8 protein family members, including motifs (KXXEXXDT, QXXFLHXYHH, NXXXHXXMYXYY and TXXQXXQ), endoplasmic reticulum (ER) retention signal, multiple membrane-spanning regions and a histidine box $(\mathrm{HXXHH})$, which is involved in the coordination of electron reception during fatty acid elongation [36]. It has been shown that the two Elovl8 isoforms may play various roles during the n-3 PUFA synthesis in different species. For instance, Elovl8b could elongate C18 (18:2n-6, 18:3n-3 and 18:4n-3) and C20 (20:4n-6 and 20:5n-3) polyunsaturated fatty acids (PUFAs) to longer-chain polyunsaturated fatty acids (LC-PUFAs), whereas Elovl8a lacked this ability in rabbitfish. However, in the study of zebrafish, Elovl8a activity was specific to C18-C20 PUFAs, just as Elovl4, Elovl5 and Elovl8b activity was specific to C18:0 and C20:1 MUFAs similar to Elovl1, Elovl3, and Elovl7 [9,19]. Thus, further studies need to explore Elovl8 functions in LC-PUFA synthesis in this hybrid grouper.

Fads2 ( $\Delta 6$ desaturase) catalyzes the first desaturation step in LC-PUFA synthesis and has been widely studied as the rate-limiting enzyme in the classical " $\Delta 6$ desaturationElovl5- $\Delta 5$ desaturation" LC-PUFA biosynthetic pathway [37]. Like all teleost fish species, phylogenetic analysis confirmed that the identified hybrid grouper cDNA was fads2 rather than fads1, while both Fads1 and Fads2 desaturases were found in Elopomorpha species such as Japanese eel (Anguilla japonica), and it was considered that Fads1 was retained in Chondrichthyes and early ray-finned fish before its subsequent loss in Osteoglossomorpha and Clupeocephala [38]. As it is compensating for the lack of Fads1 in teleost genomes, Fads2 have functionally diversified during their evolution, such that $\Delta 6, \Delta 4, \Delta 5, \Delta 8$, or bifunctional desaturation abilities have been recorded in different fish species. Moreover, it has been demonstrated that the low expression of the fads2 gene in carnivorous marine species was due to the lack of a binding site for stimulatory protein 1 (Sp1) [39]. 
The analysis of tissue distribution patterns for genes is helpful to better understand their physiological roles. Our study showed that the gene expression of elovl5, elovl8, and fads 2 was detected in all the examined tissues, which was consistent with the ubiquitous expression previously reported in fish $[18,19,28]$. Furthermore, these three genes were predominantly expressed in the brains of hybrid groupers, as reported in other carnivorous marine fish species, including groupers and other species, such as cobia [40], Asian seabass (Lates calcarifer) [41], Nibe croaker (Nibea mitsukurii) [22], and Northern pike (Esox lucius) [42]. However, inconsistently with the elovl $b \mathrm{~b}$ distribution pattern in the tissues, the elovl $a$ a was highly expressed in the heart and spleen of rabbitfish, which demonstrates their various roles in the LC-PUFA synthesis process. DHA is one of the most abundant LC-PUFA in the brain and is vital for brain function and development; this is the likely reason for elovl5, elovl8 and fads2 being highly expressed, to supply the high requirements for this tissue. However, studies in freshwater and marine herbivorous species such as rabbitfish and Atlantic salmon $[11,18]$ showed that the liver and intestine, as the significant metabolic sites for LC-PUFA biosynthesis, exhibited the highest expression of elovl5 and fads 2 genes. In addition, our study also showed that relatively higher gene expressions of elovl5 were found in pyloric ceca compared with intestine and muscle, which indicated that it could be an important site of LC-PUFA, as reported in rainbow trout [43]. However, the gene expression in the kidney was the lowest among all the measured tissue, which was inconsistent with the orange-spotted grouper findings [44]. These results suggest that the diversification of fish LC-PUFA synthesis in different tissues could be associated with factors such as feeding habits, ecological habits, and species-specific evolutionary history [45].

Marine fish species' requirement for LC-PUFA firstly depends on daily intake from the diet. As alternative oil sources lacking in LC-PUFA are gradually being used in the diet, it is essential to clarify the patterns of dietary fatty acids in regulating genes encoding desaturases and elongases in farmed fish. As the liver serves as the primary site for FA metabolism, including de novo synthesis of FA, we evaluated the gene expression of elovl5, elovl8 and fads 2 in the liver of hybrid groupers, and they were down-regulated by higher dietary n-3 LC-PUFA levels, which was consistent with the findings in the orange-spotted grouper [28,29,44] and other fish species such as the large yellow croaker [46]. These observations reflect the negative feedback regulation of the LC-PUFA synthetic pathway. Atlantic salmon elovl5 reporter activities were induced by the overexpression of $\mathrm{LXR} \alpha$, but not by the overexpression of sterol regulatory element-binding protein 1 (SREBP-1) [47]. In a study of Japanese seabass, CpG methylation of the fads2 promoter was observed as hepatic fads2 expression decreased in response to high dietary n-3 LC-PUFA, but a similar result was not recorded in European seabass [48]. Thus, further investigation is required to explore the regulation mechanism related to the different genes involved in LC-PUFA for hybrid groupers.

\section{Conclusions}

In summary, elovl5, elovl8 and fads2 genes were identified from hybrid groupers. The characteristics of the above genes were similar to other marine teleost fish species. Moreover, elovl5, elovl8 and fads2 were broadly expressed in most tissues, with the highest levels being found in the brain and liver, followed by the stomach, and the lowest levels being found in the kidney. Furthermore, the hepatic gene expression of elovl5, elovls and fads 2 was downregulated by high dietary n-3 LC-PUFA. However, future studies are needed to determine the functional characterization of these genes and to explore the mechanism of these genes when regulated by the dietary fatty lipid profiles to better understand the process of n-3 LC-PUFAs biosynthesis in this fish species.

Supplementary Materials: The following are available online at https:/ / www.mdpi.com/article/ 10.3390/ani12030234/s1. Figure S1: Multiple Sequence Alignment of elovl5, elovl8 and fads2 genes used for primer design. The design sequence of the primers is marked with square, Figure S2: Maximum likelihood method parameters, Figure S3: Effect of dietary n-3 LC-PUFA levels (g/100 g) on weight gain (\%) of hybrid grouper, Figure S4: Nucleotide and deduced amino acid sequence 
of Elovl5 in hybrid grouper (GenBank accession number MZ713365). The nucleotide sequence is numbered from the first base at $5^{\prime}$ end, started in codon (ATG) and stopped in codon (TGA). Four conserved motif of elongases are in gray; the putative histidine-richdomain (HXXHH) is in bold; the predicted seven (I-VII) putative membrane-spanning domains are underlined; the ER retrieval signal is wavy underlined, Figure S5: Nucleotide and deduced amino acid sequence of Elov18 in hybrid grouper (GenBank accession number MZ713364). The nucleotide sequence is numbered from the first base at $5^{\prime}$ end, started in codon (ATG) and stopped in codon (TGA). The putative transmembrane regions are in gray; the putative histidine-richdomain $(\mathrm{HXXHH)}$ is in bold; the predicted seven (I-VII) putative membrane-spanning domains are underlined; the ER retrieval signal is wavy underlined, Figure S6: Nucleotide and deduced amino acid sequence of Fads2 in hybrid grouper (GenBank accession number MZ713366). The nucleotide sequence is numbered from the first base at the $5^{\prime}$ end, started in codon (ATG) and stopped in codon (TGA). The Cytochrome b5-like Heme/Steroid binding domain is in gray; the putative histidine-rich domain (HXXHH, HDXGH and QXXHH) is in bold; the predicted four (I-IV) putative membrane-spanning domains are underlined.

Author Contributions: Q.W. manuscript preparation; C.W. and Y.W. investigation; Z.Z. and Y.S. formal analysis; Y.G. conceptualization and writing-review and editing. All authors have read and agreed to the published version of the manuscript.

Funding: This research was supported by the Key Research Project of Hainan Province (ZDYF2019099) and National Natural Science Foundation of China (31802313).

Institutional Review Board Statement: The protocol of animal experiment was reviewed and approved by the Committee of Animal Welfare and Ethics of Hainan University (The project identification code: HNUAUCC-2021-00085).

Informed Consent Statement: Not applicable.

Data Availability Statement: Data are available on request from the corresponding author.

Acknowledgments: We appreciate the Analytical and Testing Center of Hainan University for the GC analysis of fatty acids.

Conflicts of Interest: The authors declare no conflict of interest.

\section{References}

1. Zhang, T.T.; Xu, J.; Wang, Y.M.; Xue, C.H. Health benefits of dietary marine DHA/EPA-enriched glycerophospholipids. Prog. Lipid Res. 2019, 75, 100997. [CrossRef] [PubMed]

2. Zárate, R.; Jaber-Vazdekis, N.; Tejera, N.; Pérez, J.A.; Rodríguez, C. Significance of long chain polyunsaturated fatty acids in human health. Clin. Transl. Med. 2017, 6, 1-19. [CrossRef] [PubMed]

3. Abedi, E.; Sahari, M.A. Long-chain polyunsaturated fatty acid sources and evaluation of their nutritional and functional properties. Food Sci. Nutr. 2014, 2, 443-463. [CrossRef] [PubMed]

4. Auchterlonie, N. The continuing importance of fishmeal and fish oil in aquafeeds. Presented at the Aquafarm Conference, Pordenone, Italy, 15-16 February 2018.

5. Bell, J.G.; Tocher, D.R.; Henderson, R.J.; Dick, J.R.; Crampton, V.O. Altered fatty acid compositions in Atlantic salmon (Salmo salar) fed diets containing linseed and rapeseed oils can be partially restored by a subsequent fish oil finishing diet. J. Nutr. 2003, 133, 2793-2801. [CrossRef] [PubMed]

6. Menoyo, D.; López-Bote, C.J.; Obach, A.; Bautista, J.M. Effect of dietary fish oil substitution with linseed oil on the performance, tissue fatty acid profile, metabolism, and oxidative stability of Atlantic salmon. J. Anim. Sci. 2005, 83, 2853-2862. [CrossRef] [PubMed]

7. Monroig, Ó.; Kabeya, N. Desaturases and elongases involved in polyunsaturated fatty acid biosynthesis in aquatic invertebrates: A comprehensive review. Fish. Sci. 2018, 84, 911-928. [CrossRef]

8. Chen, C.; Zhang, M.; Li, Y.; Wang, S.; Xie, D.; Wen, X.; Monroig, Ó. Identification of miR-145 as a Key Regulator Involved in LC-PUFA Biosynthesis by Targeting hnf $4 \alpha$ in the Marine Teleost Siganus canaliculatus. J. Agric. Food Chem. 2020, 68, 15123-15133. [CrossRef]

9. Sun, S.; Wang, Y.; Goh, P.T.; Lopes-Marques, M.; Castro, L.F.C.; Monroig, Ó.; Gao, J. Evolution and Functional Characteristics of the Novel elovl8 That Play Pivotal Roles in Fatty Acid Biosynthesis. Genes 2021, 12, 1287. [CrossRef]

10. Monroig, O.; Rotllant, J.; Sanchez, E.; Cerda-Reverter, J.M.; Tocher, D.R. Expression of long-chain polyunsaturated fatty acid (LC-PUFA) biosynthesis genes during zebrafish Danio rerio early embryogenesis. BBA Mol. Cell Biol. Lipids 2009, 1791, $1093-1101$. [CrossRef] 
11. Morais, S.; Monroig, O.; Zheng, X.; Leaver, M.; Tocher, D. Highly unsaturated fatty acid synthesis in Atlantic Salmon: Characterization of ELOVL5- and ELOVL2-like elongases. Mar. Biotechnol. 2009, 11, 627-639. [CrossRef] [PubMed]

12. Gregory, M.K.; James, M.J. Rainbow trout (Oncorhynchus mykiss) Elovl5 and Elovl2 differ in selectivity for elongation of omega-3 docosapentaenoic acid. BBA Mol. Cell Biol. Lipids 2014, 1841, 1656-1660. [CrossRef] [PubMed]

13. Oboh, A.; Betancor, M.B.; Tocher, D.R.; Monroig, O. Biosynthesis of longchain polyunsaturated fatty acids in the African catfish Clarias gariepinus: Molecular cloning and functional characterisation of fatty acyl desaturase (fads2) and elongase (elovl2) cDNAs. Aquaculture 2016, 462, 70-79. [CrossRef]

14. Monroig, O.; Lopes-Marques, M.; Navarro, J.C. Evolutionary functional elaboration of the Elovl2/5 gene family in chordates. Sci. Rep. 2016, 6, 20510. [CrossRef]

15. Monroig, Ó.; Navarro, J.C.; Tocher, D.R. Long-chain polyunsaturated fatty acids in fish: Recent advances on desaturases and elongases involved in their biosynthesis. In Proceedings of the Avances en Nutrición Acuícola XI-Memorias del Décimo Primer Simposio Internacional de Nutrición Acuícola, San Nicolás de los Garza, Mexico, 23-25 November 2011; pp. $257-283$.

16. Castro, L.F.C.; Tocher, D.R.; Monroig, O. Long-chain polyunsaturated fatty acid biosynthesis in chordates: Insights into the evolution of Fads and Elovl gene repertoire. Prog. Lipid Res. 2016, 62, 25-40. [CrossRef] [PubMed]

17. Leonard, A.E.; Kelder, B.; Bobik, E.G.; Chuang, L.T.; Lewis, C.J.; Kopchick, J.J.; Mukerji, P.; Huang, Y.S. Identification and expression of mammalian long-chain PUFA elongation enzymes. Lipids 2002, 37, 733-740. [CrossRef]

18. Monroig, O.; Wang, S.; Zhang, L.; You, C.; Tocher, D.R.; Li, Y. Elongation of long-chain fatty acids in rabbitfish Siganus canaliculatus: Cloning, functional characterisation and tissue distribution of Elovl5-and Elovl4-like elongases. Aquaculture 2012, 350, 63-70. [CrossRef]

19. Li, Y.; Wen, Z.; You, C.; Xie, Z.; Li, Y. Genome wide identification and functional characterization of two LC-PUFA biosynthesis elongase (elovl8) genes in rabbitfish (Siganus canaliculatus). Aquaculture 2020, 522, 735127.

20. Sprecher, H.; Luthria, D.L.; Mohammed, B.S.; Baykousheva, S.P. Reevaluation of the pathways for the biosynthesis of polyunsaturated fatty acids. J. Lipid Res. 1995, 36, 2471-2477. [CrossRef]

21. Marquardt, A.; Stöhr, H.; White, K.; Weber, B.H. cDNA cloning, genomic structure, and chromosomal localization of three members of the human fatty acid desaturase family. Genomics 2000, 66, 175-183. [CrossRef] [PubMed]

22. Kabeya, N.; Yamamoto, Y.; Cummins, S.F.; Elizur, A.; Yazawa, R.; Takeuchi, Y.; Yoshizaki, G. Polyunsaturated fatty acid metabolism in a marine teleost, Nibe croaker Nibea mitsukurii: Functional characterization of Fads2 desaturase and Elovl5 and Elovl4 elongases. Comp. Biochem. Physiol. Part B Biochem. 2015, 188, 37-45. [CrossRef] [PubMed]

23. Abdul Hamid, N.K.; Carmona-Antonanzas, G.; Monroig, O.; Tocher, D.R.; Turchini, G.M.; Donald, J.A. Isolation and functional characterisation of a fads2 in rainbow trout (Oncorhynchus mykiss) with $\Delta 5$ desaturase activity. PLoS ONE 2016, 11, 0150770. [CrossRef] [PubMed]

24. Li, Y.; Monroig, O.; Zhang, L.; Wang, S.; Zheng, X.; Dick, J.R. Vertebrate fatty acyl desaturase with $\Delta 4$ activity. Proc. Natl. Acad. Sci. USA 2010, 107, 16840-16845. [CrossRef] [PubMed]

25. Morais, S.; Castanheira, F.; Martínez-Rubio, L.; Conceição, L.E.C.; Tocher, D.R. Long-chain polyunsaturated fatty acid synthesis in a marine vertebrate: Ontogenetic and nutritional regulation of a fatty acyl desaturase with $\Delta 4$ activity. Biochim. Biophys. Acta 2012, 1821, 660-671. [CrossRef] [PubMed]

26. Yearbook, C.F.S. China Fishery Statistics Yearbook; Bureau of Fisheries, Ministry of Agriculture: Beijing, China, 2021.

27. Sun, Y.; Guo, C.Y.; Wang, D.D.; Li, X.F.; Xiao, L.; Zhang, X.; Zhang, Y. Transcriptome analysis reveals the molecular mechanisms underlying growth superiority in a novel grouper hybrid (Epinephelus fuscogutatus $\times$ ×. Eanceolatusơ). BMC Genet. 2016, 17, 1-10. [CrossRef] [PubMed]

28. Li, S.; Mai, K.; Xu, W.; Yuan, Y.; Zhang, Y.; Ai, Q. Characterization, mRNA expression and regulation of $\Delta 6$ fatty acyl desaturase (FADS2) by dietary n-3 long chain polyunsaturated fatty acid (LC-PUFA) levels in grouper larvae (Epinephelus coioides). Aquaculture 2014, 434, 212-219. [CrossRef]

29. Li, S.; Monroig, Ó; Navarro, J.C.; Yuan, Y.; Xu, W.; Mai, K.; Ai, Q. Molecular cloning and functional characterization of a putative Elovl4 gene and its expression in response to dietary fatty acid profiles in orange-spotted grouper Epinephelus coioides. Aquacult. Res. 2017, 48, 537-552. [CrossRef]

30. Baoshan, L.; Jiying, W.; Yu, H.; Tiantian, H.; Shixin, W.; BingShan, H.; Yongzhi, S. Effects of replacing fish oil with wheat germ oil on growth, fat deposition, serum biochemical indices and lipid metabolic enzyme of juvenile hybrid grouper (Epinephelus fuscoguttatus $+\times$ Epinephelus lanceolatuso' $)$. Aquaculture 2019, 505, 54-62. [CrossRef]

31. Yong, A.S.K.; Mubarak, N.S.S.; Shapawi, R. Effects of partial replacement of fish oil with different vegetable oils on growth, feed utilization and fatty acid profile of hybrid grouper juvenile (Epinephelus fuscoguttatus x Epinephelus lanceolatus). J. Oil Palm Res. 2019, 31, 110-121.

32. An, W.; Dong, X.; Tan, B.; Wu, M.; Zhang, S.; Chi, S.; Yang, Y. Effects of dietary vegetable oil on growth performance, digestive capacity, antioxidant capacity and expression of immune-related genes in the hybrid grouper (Epinephelus fuscoguttatus $9 \times$ E. lanceolatuso'). Aquacult. Nutr. 2020, 26, 2086-2101. [CrossRef]

33. Yan, X.; Dong, X.; Tan, B.; Zhang, S.; Chi, S.; Liu, H.; Yang, Y. Effects of alternative dietary oils on lipid metabolism and related gene expression in hybrid grouper (Epinephelus fuscoguttatuso $\times \sigma^{7}$ E. lanceolatu). Aquacult. Nutr. 2021, 27, 105-115. [CrossRef]

34. Xie, D.; Chen, C.; Dong, Y.; You, C.; Wang, S.; Monroig, Ó.; Li, Y. Regulation of long-chain polyunsaturated fatty acid biosynthesis in teleost fish. Prog. Lipid Res. 2021, 36, 2471-2477. [CrossRef] [PubMed] 
35. Meyer, A.; Kirsch, H.; Domergue, F.; Abbadi, A.; Sperling, P.; Bauer, J.; Cirpus, P.; Zank, T.K.; Moreau, H.; Roscoe, T.J. Novel fatty acid elongases and their use for the reconstitution of docosahexaenoic acid biosynthesis. J. Lipid Res. 2004, 45, 1899-1909. [CrossRef] [PubMed]

36. Jakobsson, A.; Westerberg, R.; Jacobsson, A. Fatty acid elongases in mammals: Their regulation and roles in metabolism. Prog. Lipid Res. 2006, 45, 237-249. [CrossRef] [PubMed]

37. Tocher, D.R.; Zheng, X.; Schlechtriem, C.; Hastings, N.; Dick, J.R.; Teale, A.J. Highly unsaturated fatty acid synthesis in marine fish: Cloning, functional characterization, and nutritional regulation of fatty acyl $\Delta 6$ desaturase of Atlantic cod (Gadus morhua L.) Lipids 2006, 41, 1003-1016. [CrossRef] [PubMed]

38. Lopes-Marques, M.; Kabeya, N.; Qian, Y.; Ruivo, R.; Santos, M.M.; Venkatesh, B.; Tocher, D.R.; Castro, L.F.C.; Monroig, Ó. Retention of fatty acyl desaturase 1 (fads1) in Elopomorpha and Cyclostomata provides novel insights into the evolution of long-chain polyunsaturated fatty acid biosynthesis in vertebrates. BMC. Evol. Biol. 2018, 18, 157. [CrossRef] [PubMed]

39. Xie, D.; Fu, Z.; Wang, S.; You, C.; Monroig, O.; Tocher, D.R.; Li, Y. Characteristics of the fads2 gene promoter in marine teleost Epinephelus coioides and role of Sp1-binding site in determining promoter activity. Sci. Rep. 2018, 8, 5305. [CrossRef] [PubMed]

40. Zheng, X.; King, Z.; Xu, Y.; Monroig, O.; Morais, S.; Tocher, D.R. Physiological roles of fatty acyl desaturases and elongases in marine fish: Characterisation of cDNAs of fatty acyl $\Delta 6$ desaturase and Elovl5 elongase of cobia (Rachycentron canadum). Aquaculture 2009, 290, 122-131. [CrossRef]

41. Mohd-Yusof, N.Y.; Monroig, Ó.; Mohd-Adnan, A.; Wan, K.-L.; Tocher, D.R. Investigation of highly unsaturated fatty acid metabolism in the Asian sea bass, Lates calcarifer. Fish Physiol. Biochem. 2010, 3, 827-843. [CrossRef]

42. Carmona-Antonanzas, G.; Tocher, D.R.; Taggart, J.B.; Leaver, M.J. An evolutionary perspective on Elovl5 fatty acid elongase: Comparison of Northern pike and duplicated paralogs from Atlantic salmon. BMC Evol. Biol. 2013, 13, 1-13. [CrossRef]

43. Bell, M.V.; Dick, J.R.; Porter, A.E. Pyloric ceca are significant site of of newly synthesized 22:6n3 in rainbow trout (Oncorhynchus mykiss). Lipids 2003, 39, 39-44. [CrossRef] [PubMed]

44. Li, S.; Yuan, Y.; Wang, T.; Xu, W.; Li, M.; Mai, K.; Ai, Q. Molecular cloning, functional characterization and nutritional regulation of the putative elongase Elovl5 in the orange-spotted grouper (Epinephelus coioides). PLoS ONE 2016, 11, 0150544. [CrossRef] [PubMed]

45. Xie, D.; Ye, J.; Lu, M.; Wang, S.; You, C.; Li, Y. Comparsion of activities of fatty acyl desaturases and elongases among six teleosts with different feeding and ecological habits. Front. Mar. Sci. 2020, 7, 117. [CrossRef]

46. Zuo, R.; Mai, K.; Xu, W.; Dong, X.; Ai, Q. Molecular cloning, tissue distribution and nutritional regulation of a fatty acyl elovl5-like elongase in large yellow croaker, Larimichthys crocea. Aquacult. Res. 2016, 47, 2393-2406. [CrossRef]

47. Minghetti, M.; Leaver, M.J.; Tocher, D.R. Transcriptional control mechanisms of genes of lipid and fatty acid metabolism in the Atlantic salmon (Salmo salar 1.) established cell line, shk-1. Biochim. Biophys. Acta 2011, 1811, 194-202. [CrossRef]

48. Geay, F.; Zambonino-Infante, J.; Reinhardt, R.; Kuhl, H.; Santigosa, E.; Cahu, C. Characteristics of Fads2 gene expression and putative promoter in European sea bass (Dicentrarchus labrax): Comparison with salmonid species and analysis of CpG methylation. Mar. Genom. 2012, 5, 7-13. [CrossRef] [PubMed] 